\title{
Remobilization of Americium in calcareous soil columns under experimental rhizospheric conditions
}

\author{
T. Perrier ${ }^{1}$, A. Martin-Garin ${ }^{1}$ and C. Mustin ${ }^{2}$ \\ ${ }^{1}$ Laboratory of Radioecology and Ecotoxicology, Institute for Radioprotection and Nuclear \\ Safety, Cadarache, BP. 3, 13115 St-Paul-lez-Durance Cedex, France \\ ${ }^{2}$ Laboratory for the Interactions Microorganisms-Minerals-Organic Matter in Soils, UMR 7137 \\ CNRS-UHP Nancy I, Faculté des Sciences, BP. 239, \\ 54506 Vandoeuvre-lès-Nancy Cedex, France
}

\begin{abstract}
The biogeochemical behaviour of americium in subsurface soils plays a dominant role on its potential migration, but is currently poorly known. This research investigates the relevant processes controlling americium biogeochemical speciation in the rhizosphere of an agricultural soil. Lixiviation tests were performed on columns packed with a calcareous soil contaminated with ${ }^{241} \mathrm{Am}$, under steady-state unsaturated or saturated hydric flow conditions. The columns were percolated with various soil solutions, containing citrate and/or glucose to simulate root exudates. The bio-physico-chemical parameters of the outlet solutions were monitored continuously. The percolation of a solution in equilibrium with the soil or containing low exudate concentrations $\left(10^{-4} \mathrm{M}\right)$ released less than $5 \mathrm{mBq} / \mathrm{cm}^{3}$ of americium. Poor remobilisations were also observed when injecting $10^{-2} \mathrm{M}$ glucose solutions, despite effective glucose microbial degradation, production of secondary ligands, and important chemical changes. On the contrary, percolation of $10^{-2} \mathrm{M}$ citrate solution released 1000 times more americium, in accordance with previous studies. 10000 times greater releases were observed when glucose was added to citrate at $10^{-2} \mathrm{M}$. The remobilisation of americium resulting from both dissolution of calcite and iron oxides, and complexation by citrate, as well as the applicability of simple parameterisation of partition coefficient are discussed.
\end{abstract}

\section{INTRODUCTION}

Americium-241, an artificial element produced during the nuclear fuel cycle, is one of the most (radio) toxic contaminants. ${ }^{241} \mathrm{Am}$ can be found in every compartment of the environment, especially soils where it concentrates due to its affinity for solid phases and organic matter. Soils constitute a potential source for surface water and groundwater diffuse and far-field contamination [1,2]. Specific biogeochemical conditions are found in the rhizosphere, i.e. the topsoil layer under the influence of plant roots. They may increase ${ }^{241} \mathrm{Am}$ remobilisation due to acidification and complexation by organic acids exudation occurring during root and soil microorganisms activities $[3,4]$, as it has been demonstrated for heavy metals [5]. Despite numerous studies on distribution patterns and inventories of ${ }^{241} \mathrm{Am}$ contamination in soils, the biogeochemical behaviour of Am in the rhizosphere is currently scarcely studied and thus poorly known [6-8]. Moreover, though it is well known that simple $K_{d}$-based transport models are insufficient to describe the complex geochemical reactions that control the distribution of solutes in subsurface environments, their use remains prevalent in the regulatory environment because of their mathematical simplicity, their low computing time and memory resources needs, and the easy measurements of $K_{d}$ values [9]. In order to improve predictive models, better understanding of the underlying processes is needed to parameterise and/or associate uncertainties to the operational values commonly used. 
The effects of simplified rhizosopheric conditions on the leaching of ${ }^{241} \mathrm{Am}$ from an artificially contaminated soil were investigated using laboratory column experiments. A sugar, glucose, and a carboxylic acid, citrate, were used as model exudates, at concentrations ranging from typical mean rhizospheric values to higher values expected in local "hotspots" [10-12]. A quantification of Am remobilisation in the different conditions is given, along with the proposed controlling mechanisms. More detailed results comparing both batch and column experiments can be found in two recent publications $[13,14]$.

\section{PROCEDURES}

\subsection{Soil and injected solutions}

A $2 \mathrm{~mm}$-sieved French agricultural soil corresponding to the A-horizon of a calcareous sandy loam was used. The soil was constituted mainly of quartz, calcite and iron oxides. The soil was artificially contaminated with ${ }^{241} \mathrm{Am}$ at $530 \mathrm{~Bq} \cdot \mathrm{g}^{-1}$ of dry soil, which still corresponded to ultra-trace surface contamination. Considering the soil's mineralogical composition and the existing literature on the affinity of americium for solid phases [15-19], it was assumed that Am was mainly associated to the prevalent reactive solid phases occurring in the soil: calcite and iron oxides.

A solution that did not modify the carbonate equilibrium of the soil was used as a background solution for all experiments. This solution, referred to as the reference solution, was artificially prepared by equilibrating ultra pure water with calcite under a $\mathrm{CO}_{2}$-enriched atmosphere. The chemical composition of the reference solution was $\mathrm{pH} 7.7,\left[\mathrm{Ca}^{2+}\right]=1.110^{-3} \mathrm{M}$ and $\left[\mathrm{HCO}_{3}^{-}\right]=2.210^{-3} \mathrm{M}$ at a $p \mathrm{CO}_{2}=10^{-2.5}$. Exudate solutions consisted in reference solution with added glucose, Na-citrate or both combined at concentrations from $10^{-4} \mathrm{M}$ to $2.510^{-2} \mathrm{M}$.

\subsection{Column experiments}

Column experiments consisted in the leaching of ${ }^{241} \mathrm{Am}$ contaminated soil under saturated or unsaturated hydric flow conditions. Experiments were performed at $23{ }^{\circ} \mathrm{C}$ at constant flow rates equal to 0.16 and $0.04 \mathrm{~mL} \cdot \mathrm{min}^{-1}$ for saturated and unsaturated columns respectively. For each condition, a sequence of solutions were injected successively, according to: (I) reference solution until a steady-flow regime and a steady Am release were reached, (II) low concentration solution until a new steady Am release was reached, and (III) high concentration solution, up to the end.

\subsection{Chemical analyses and ${ }^{241} \mathrm{Am}$ counting}

Chemical analyses were performed on column leachates either online or after sampling collections. They consisted in the monitoring of ${ }^{241} \mathrm{Am}, \mathrm{pH}$, conductivity, alkalinity, major ions, total Iron $\left(\mathrm{Fe}_{\mathrm{T}}\right)$, glucose, citrate and other organic acids such as acetate and malate. $\mathrm{Ca}^{2+}$ and $\mathrm{Fe}_{\mathrm{T}}$ concentrations were used to evaluate the dissolution of calcite and iron oxides respectively by comparing input and output solution compositions. ${ }^{241} \mathrm{Am}$ concentrations were determined by - liquid scintillation counting, with a minimum detectable activity of $10^{-2} \mathrm{~Bq}$.

\subsection{Determination of a column $K_{d}$}

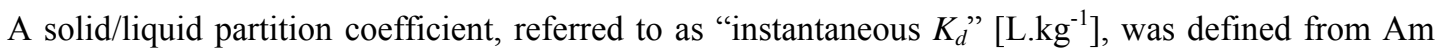
breakthrough curves (BTC) as the fraction between ${ }^{241} \mathrm{Am}$ concentration still on the solid phase (considered homogeneous all along the column) and the concentration in the eluate, at a given time $t$. 


\section{RESULTS AND DISCUSSION}

\section{$3.1{ }^{241} \mathrm{Am}$ remobilisation}

The remobilisation of Am in the columns was contrasted and highly dependent on the injected solution. ${ }^{241} \mathrm{Am}$ breakthrough curves showed a 3-stage pattern, in accordance with the injection sequence. The example of the Na-citrate column is shown on Fig.1. The first stage (reference solution) was characterized by a transitory state with facilitated Am transport followed by low steady releases. Poor steady Am release was observed during the percolation of low concentration exudate solutions. Finally, a transitory state with generally high Am release was observed during the percolation of high concentration exudates solutions, in parallel with the degradation of the porous media, leading to the column's breakdown.

${ }^{241}$ Am concentrations (mean and maximum values) of the leachates for the different conditions in both saturated and unsaturated columns are reported in Tab.1, as well as the corresponding calculated instantaneous $K_{d}$ values. During the first pore volumes of leaching with the reference solution, colloidal Am transport was observed both in saturated and unsaturated columns (up to 20 to $100 \mathrm{~Bq} \cdot \mathrm{L}^{-1}$ ). That highly mobile Am corresponded to a limited pool representing less than $1 \%$ of the total ${ }^{241}$ Am column contamination, but constituting more than $90 \%$ of the total amount of desorbed Am in poorly desorbing conditions [13]. The following pore volumes leached with reference solution induced steady and low Am releases ranging from 4 to $12 \mathrm{~Bq} . \mathrm{L}^{-1}$, corresponding to $K_{d}$ of about 43 to $13010^{5} \mathrm{~L}_{\mathrm{kg}} \mathrm{kg}^{-1}$, as reported previously for such reactive soil phases [18,20-22]. No major differences were observed in columns between unsaturated and saturated columns, except from a slight higher Am release in unsaturated columns. The shift to low concentration solutions (glucose, Na-citrate or glucose $+\mathrm{Na}$-citrate at $10^{-4} \mathrm{M}$ ) didn't modify Am remobilisation. In these conditions, glucose and/or Na-citrate were completely degraded or adsorbed inside the column, without inducing significant chemical changes in the solution. The soil carbonate buffer did probably flatten the acidification caused by the biodegradation of exudates by dissolving small amounts of calcite, even if it was not revealed by a significant $\mathrm{Ca}^{2+}$ increase in the leachates.

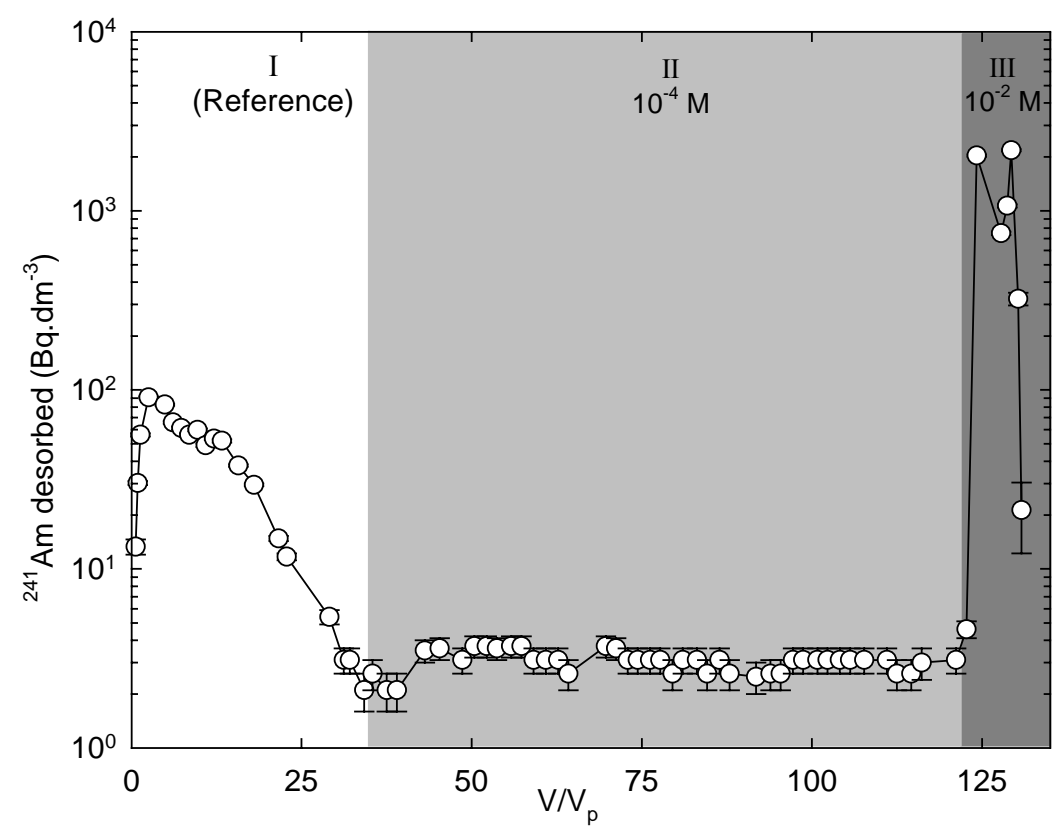

Figure 1. Typical ${ }^{241} \mathrm{Am}$ breakthrough curve obtained in column experiments (example shown: Na-citrate condition in saturated column). 
Table 1. ${ }^{241}$ Am concentrations and $K_{d}$ values during column experiments.

\begin{tabular}{|c|c|c|c|}
\hline Conditions & $\begin{array}{c}\text { Exudate } \\
\text { concentration } \\
\left(\text { mol. }^{-1}\right)\end{array}$ & $\begin{array}{c}{ }^{241} \mathrm{Am} \pm 5 \% \\
\text { mean } / \max \\
\left(\mathrm{Bq} \cdot \mathrm{L}^{-1}\right)\end{array}$ & $\begin{array}{c}K_{d} \pm 7 \% \\
\text { from mean / max } \\
\left({\left.\mathrm{L} . \mathrm{kg}^{-1}\right)}^{2}\right.\end{array}$ \\
\hline \multicolumn{4}{|l|}{ Saturated columns } \\
\hline Reference & 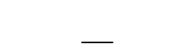 & $7 / 12$ & $78000 / 44000$ \\
\hline (colloidal) & & $(26 / 91)$ & $(20000 / 6000)$ \\
\hline All exudates & $10^{-4}$ & $3 / 8$ & $170000 / 65000$ \\
\hline Glucose + Na-citrate & $10^{-3}$ & $5 / 9$ & $113000 / 58000$ \\
\hline Glucose & $10^{-2}$ & $22 / \mathrm{nd}$ & $24000 / \mathrm{nd}$ \\
\hline Na-citrate & $10^{-2}$ & $1225 / 2180$ & $433 / 243$ \\
\hline Glucose + Na-citrate & $10^{-2}$ & $5150 / 11430$ & $103 / 46$ \\
\hline Glucose + Na-citrate & $2.510^{-2}$ & $17370 / 34435$ & $31 / 15$ \\
\hline \multicolumn{4}{|l|}{ Unsaturated columns } \\
\hline $\begin{array}{l}\text { Reference } \\
\text { (colloidal) }\end{array}$ & - & $\begin{array}{c}12 / 14 \\
(96 / 1380)\end{array}$ & $\begin{array}{c}43000 / 38000 \\
(5500 / 400)\end{array}$ \\
\hline Glucose & $10^{-4}$ & $6 / 6$ & $81000 / 81000$ \\
\hline Glucose & $10^{-3}$ & $6 / 7$ & $95000 / 75000$ \\
\hline Glucose & $10^{-2}$ & $6 / 8$ & 92000 / 68000 \\
\hline
\end{tabular}

At higher concentrations of exudates, contrasting results were observed. Glucose at $10^{-2} \mathrm{M}$ did not enhance Am remobilisation more than 2 to 5 times Am remobilisation observed with the reference solution, despite a complete degradation of glucose associated with a decrease in $\mathrm{pH}$ from 7.7 to 6 and an important dissolution of both calcite and iron oxides inside the column [13]. On the opposite, a similar concentration of $10^{-2} \mathrm{M} \mathrm{Na}$-citrate led to Am releases up to $2000 \mathrm{~Bq} \cdot \mathrm{L}^{-1}$, which were 300 times higher than the reference condition. Even greater Am releases were obtained when glucose was added to citrate at concentrations $\geq 10^{-2} \mathrm{M}$. Finally, the total range of ${ }^{241} \mathrm{Am}$ released in solution under the different conditions covered about 4 orders of magnitude.

\subsection{Effect of the dissolution of calcite and iron oxides and complexation by citrate on ${ }^{241}$ Am remobilisation}

The results showed that ${ }^{241} \mathrm{Am}$ desorption was mostly proportional to the dissolution of both calcite and iron oxides, as summarized on the correlation diagrams Fig. $2 \mathrm{~A}$ and B.

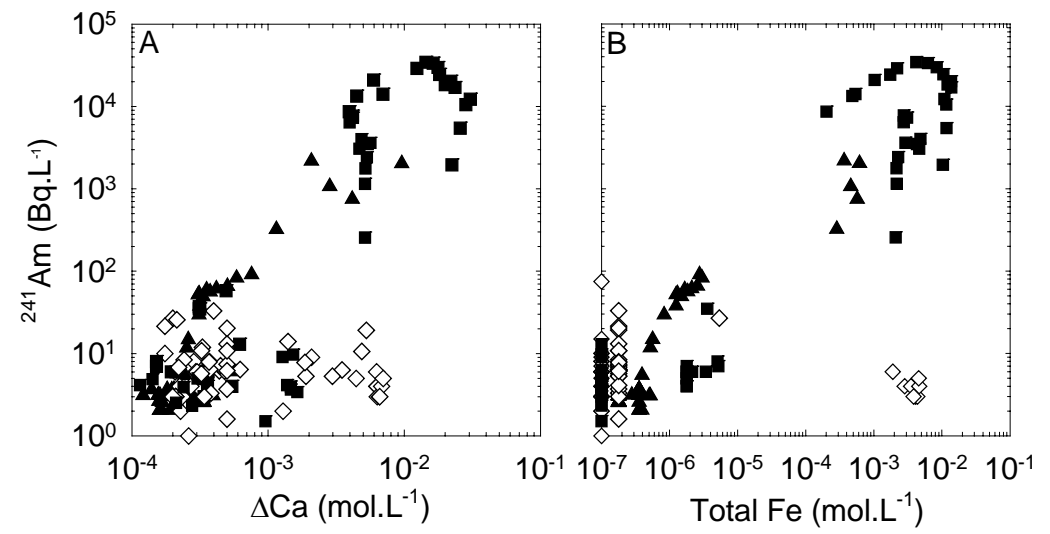

Figure 2. Correlation between ${ }^{241} \mathrm{Am}$ and dissolved $\mathrm{Ca}$ (A) and total $\mathrm{Fe}$ (B) in columns' output solutions. Columns conditions: glucose $(\diamond)$, citrate $(\boldsymbol{A})$ and glucose + citrate $(\boldsymbol{\square})$. No distinction between saturated and unsaturated columns is made. 
Though, it appears that dissolution was not sufficient to explain Am remobilisation. Indeed, conditions where glucose was solely injected did not follow that tendency: poor Am release was observed despite high calcite and iron oxides dissolution. In these conditions, Am probably underwent rapid re-precipitation or re-adsorption on the solid phases downstream [17]. The presence of citrate was thus necessary to take on and carry Am outside of the column. In those cases, several processes probably occurred simultaneously among which aqueous complexation of Am by citrate and the enhancement of calcite and iron oxides dissolutions due to Fe and Ca complexation by citrate, and the acidification after citrate biodegradation [13,23,24].

\subsection{Limits of a simple parameterisation of the $K_{d}$}

Several problems appear when trying to quantify and propose a hierarchy of the different processes, for a simplification for use in risk assessment models. Experimentally, the acquisition of more detailed information on the processes is difficult if not worthless. On one hand, simple analyses such as the macroscopic determination of ${ }^{241} \mathrm{Am}$ contamination (and other elements) soil profiles give poor results [13]. On the other hand, direct investigations of both Am solution speciation and Am interactions with solid phases at microscopic scales are almost impossible at such trace levels. Finally, the whole set of biogeochemical processes also needs a dynamic (spatial and temporal) understanding that can hardly ever be obtained. In fact, the observed complexity of such systems results more from numerous and crossed interconnections between the different processes than from the proper complexity of the different processes studied separately (dissolution/precipitation, complexation, biodegradation, transport). The understanding and quantification of each mechanism, independently from the others, seems therefore of limited use for integrated modelling.

In an attempt to overcome that kind of problems, a simple parameterisation of operational tools such as risk assessment models based on $K_{d}$ is sometimes used. The $\mathrm{pH}$ is usually chosen as an adjustment parameter for $K_{d}$ on a given soil. Easily measured, $\mathrm{pH}$ is indeed a key parameter that controls the dissolution of numerous solid phases and that plays an important role in adsorption phenomena [18]. Unfortunately, $\mathrm{pH}$ generally results more from a multitude of processes, than it is a fixed parameter that controls the others, especially in complex systems such as the rhizosphere. The consequence is that a single $\mathrm{pH}$ value is unable to explain the mobility of Am in those systems, as shown in Fig.3.

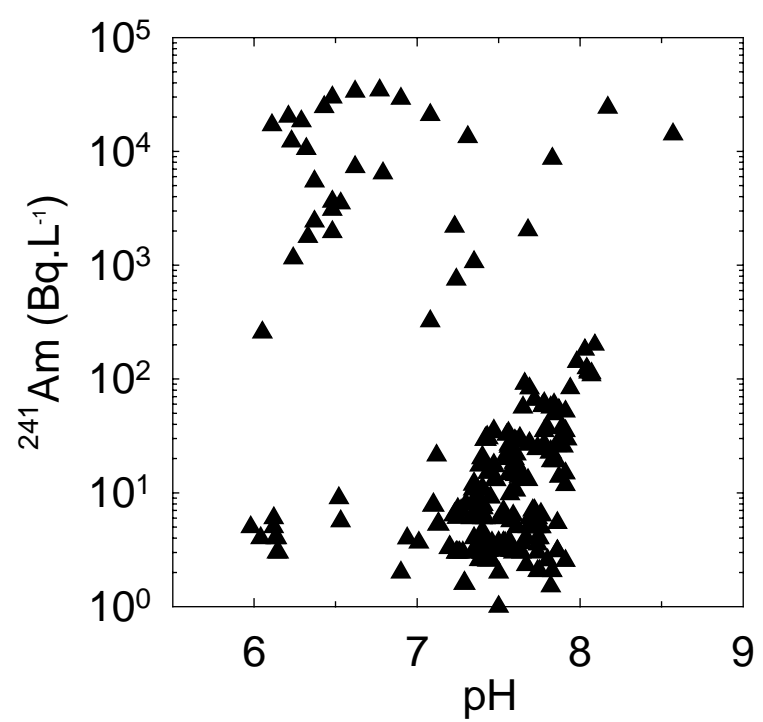

Figure 3. Correlation between ${ }^{241} \mathrm{Am}$ and $\mathrm{pH}$ in column output solutions. All the tested conditions are reported. 


\section{CONCLUSIONS}

This study has shown that several interconnecting biogeochemical processes occurred in a contaminated calcareous soil submitted to simplified rhizospheric conditions, leading to contrasted ${ }^{241} \mathrm{Am}$ releases. Simple $K_{d}$ parameterisations for risk assessment models fell in such complex and reactive systems. Yet, in natural and field scale conditions, remobilisation would probably be different, but still displaying a general trend of poor mobility with pools of highly mobile Am. Therefore, some new modelling approaches has to be proposed to better take into account Am migration availability under various bio-geochemichal constraints and especially to better describe the impact of transitory phenomena.

\section{Acknowledgments}

The authors are grateful to M. Morello, D. Orjollet and F. Cuiné for their help in the performing of chemical analyses.

\section{References}

[1] McCarthy J.F., et al., J. Contam. Hydrol 30 (1998) 49-77.

[2] Artinger R., et al., Environ. Sci. Technol 36 (2002) 4818-4823.

[3] Carlsen L., EUR 12024 (CEC report, 1989)

[4] Lu N. et al., Environ. Sci. Technol 32 (1998) 370-374.

[5] Banks M.K., et al., Chemosphere 29 (1994) 1691-1699.

[6] Kelly E.J., et al., J. Alloy. Compd 271 (1998) 227-230.

[7] Keith-Roach M.J. and Livens F., Interactions of microorganisms with radionuclides (Elsevier, 2002) Vol. 2, pp 101-141.

[8] Sokolik G.A., et al., Radiochemistry 45 (2003) 176-181.

[9] Zhu C., Computers \& Geosciences 29 (2003) 351-359.

[10] Burckhard S.R., et al., J. Hazard. Mater. 41 (1995) 135-145.

[11] Jones D.L., Plant Soil 205 (1998) 25-44.

[12] Jones D.L., et al., Plant Soil 248 (2003) 31-41.

[13] Perrier T., Etude théorique et expérimentale du comportement biogéochimique de l'Américium

241 en conditions rhizosphériques simplifiées (Université Henri Poincaré, Nancy I, 2004).

[14] Perrier T., et al., J. Environ. Radioact. (2004), in press.

[15] Moulin V., et al., Appl. Geochem. Suppl. Issue (1992) 163-166.

[16] Degueldre C., et al., Radiochim. Acta 65 (1994) 173-179.

[17] Curti E., Appl. Geochem. 14 (1999) 433-445.

[18] Zhang, P.C., Geochemistry of soil radionuclides (SSSA, 2002) Number 59.

[19] Lakshtanov L.Z., et al., Geochimica et Cosmochimica Acta 68 (2004) 819-827.

[20] Carbol P., et al., SKB R-97-13, (Swedish Nuclear Fuel and Waste Management Co, 1997).

[21] Jacquier P., et al., Appl. Geochem. 16 (2001) 85-83.

[22] Degueldre C., et al., J. Environ. Radioact. 55 (2001) 241-253.

[23] Jones D.L., et al., Plant Soil 180 (1996) 57 -66.

[24] Banaszak J.E., et al., Radiochim. Acta 82 (1998) 445-451. 